\title{
Light Water Reactor Sustainability Program
}

\author{
Reactor Pressure Vessel
}

Fracture Analysis Capabilities in Grizzly

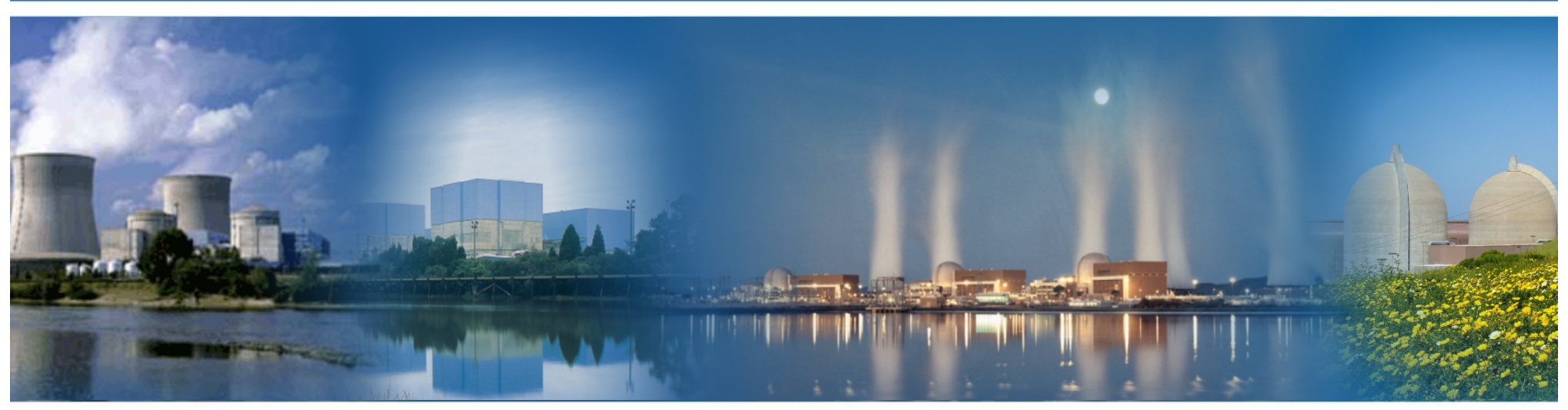

March 2015

DOE Office of Nuclear Energy 


\section{DISCLAIMER}

This information was prepared as an account of work sponsored by an agency of the U.S. Government. Neither the U.S. Government nor any agency thereof, nor any of their employees, makes any warranty, expressed or implied, or assumes any legal liability or responsibility for the accuracy, completeness, or usefulness, of any information, apparatus, product, or process disclosed, or represents that its use would not infringe privately owned rights. References herein to any specific commercial product, process, or service by trade name, trade mark, manufacturer, or otherwise, do not necessarily constitute or imply its endorsement, recommendation, or favoring by the U.S. Government or any agency thereof. The views and opinions of authors expressed herein do not necessarily state or reflect those of the U.S. Government or any agency thereof. 
INL/EXT-15-34736

\title{
Light Water Reactor Sustainability Program
}

\author{
Reactor Pressure Vessel \\ Fracture Analysis Capabilities in Grizzly \\ Benjamin Spencer ${ }^{1}$, Marie Backman ${ }^{2}$, \\ Pritam Chakraborty ${ }^{1}$, William Hoffman ${ }^{3}$ \\ ${ }^{1}$ Idaho National Laboratory \\ ${ }^{2}$ University of Tennessee \\ ${ }^{3}$ University of Idaho \\ March 2015
}

Idaho National Laboratory

Idaho Falls, Idaho 83415

http://www.inl.gov/lwrs

Prepared for the

U.S. Department of Energy

Office of Nuclear Energy

Under DOE Idaho Operations Office

Contract DE-AC07-05ID14517 


\section{EXECUTIVE SUMMARY}

Efforts are underway to develop fracture mechanics capabilities in the Grizzly code to enable it to be used to perform deterministic fracture assessments of degraded reactor pressure vessels (RPVs). A capability was previously developed to calculate $J$-integrals. For this application, these are used to calculate stress intensity factors for cracks to be used in deterministic linear elastic fracture mechanics (LEFM) assessments of fracture in degraded RPVs.

The $J$-integral can only be used to evaluate stress intensity factors for axis-aligned flaws because it can only be used to obtain the stress intensity factor for pure Mode I loading. Off-axis flaws will be subjected to mixed-mode loading. For this reason, work has continued to expand the set of fracture mechanics capabilities to permit it to evaluate off-axis flaws.

This report documents the following work to enhance Grizzly's engineering fracture mechanics capabilities for RPVs:

- Interaction Integral and $T$-stress: To obtain mixed-mode stress intensity factors, a capability to evaluate interaction integrals for $2 \mathrm{D}$ or $3 \mathrm{D}$ flaws has been developed. A $T$-stress evaluation capability has been developed to evaluate the constraint at crack tips in $2 \mathrm{D}$ or $3 \mathrm{D}$. Initial verification testing of these capabilities is documented here.

- Benchmarking for axis-aligned flaws: Grizzly's capabilities to evaluate stress intensity factors for axis-aligned flaws have been benchmarked against calculations for the same conditions in FAVOR.

- Off-axis flaw demonstration The newly-developed interaction integral capabilities are demonstrated in an application to calculate the mixed-mode stress intensity factors for off-axis flaws.

- Other code enhancements Other enhancements to the thermomechanics capabilities that relate to the solution of the engineering RPV fracture problem are documented here. 


\section{CONTENTS}

FIGURES

TABLES $\quad$ v

1 Introduction $\quad 1$

2 Interaction integrals $\quad 2$

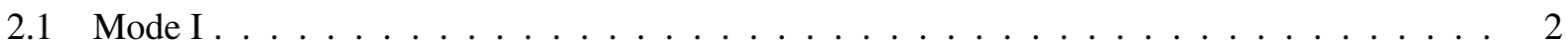

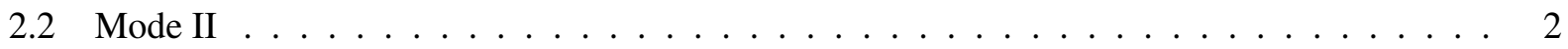

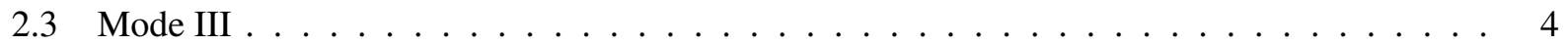

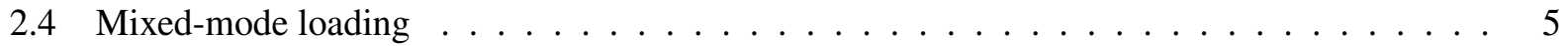

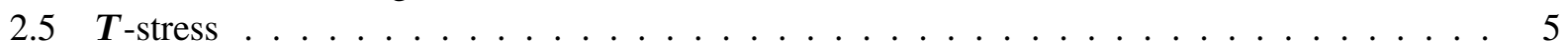

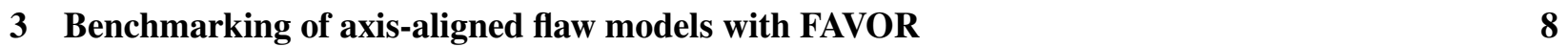

4 Analysis of off-axis flaws $\quad 11$

5 Other Code Enhancements $\quad 14$

5.1 Temperature-dependent thermal expansion . . . . . . . . . . . . . . . . . . . . . 14

5.2 Stress profile extraction . . . . . . . . . . . . . . . . . . . . . . 14

6 Summary $\quad 16$

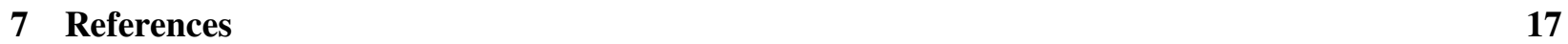




\section{FIGURES}

1 Closeup showing the crack front region of the elliptical flaw mesh. . . . . . . . . . 3

2 Mode I stress intensity factor along the crack front of a semi-elliptical surface-breaking flaw compared with an empirical formula . . . . . . . . . . . . . . . . 3

3 Two-dimensional model of an angled through crack in an infinite plate. . . . . . . . . . . 4

4 Cross section of cylinder model with a penny-shaped crack. . . . . . . . . . . . 5

5 Mesh representing a $360^{\circ}$ sector around a crack tip. . . . . . . . . . . . . . 6

$6 \quad T$-stress along the crack front of a penny-shaped crack under tension calculated with Grizzly and compared with analytical solution. . . . . . . . . . . . . . . . 7

7 Meshes used for global RPV model and local model of surface-breaking circumferential flaw

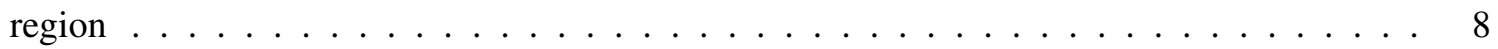

8 Time histories of coolant temperature and pressure applied to RPV . . . . . . . . . . . . 9

9 Comparison of time histories of $K_{\mathrm{I}}$ between Grizzly and FAVOR ～. . . . . . . . . . . . 10

10 Cross section of the crack region of meshes representing penny-shaped flaws in various ori-

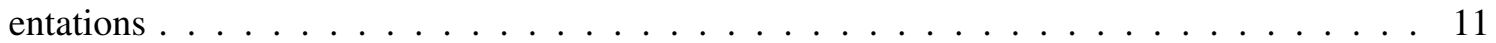

11 Time histories of Mode I stress intensity factors for various locations on flaws oriented at 0 , 10, and 15 degrees off-axis. . . . . . . . . . . . . . . . . . . . . . . 12

12 Time histories of Mode II stress intensity factors for various locations on flaws oriented at 0 , 10 , and 15 degrees off-axis. . . . . . . . . . . . . . . . . . 13

13 Time histories of Mode III stress intensity factors for various locations on flaws oriented at 0,10 , and 15 degrees off-axis. . . . . . . . . . . . . . . . . 13

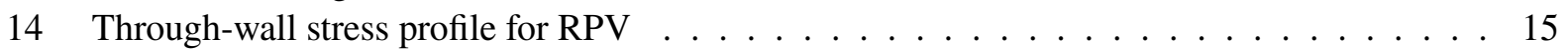




\section{TABLES}

1 Stress intensity factors for a crack in an infinite plate under a uniaxial tensile load. . . . . . 2

2 Mode III stress intensity factor for a 3D model of penny-shaped crack in cylinder under torsion. 5

3 Stress intensity factors for $360^{\circ}$ model of crack front with displacements corresponding to $K_{\mathrm{I}}=K_{\mathrm{II}}=K_{\mathrm{III}}=1.0 \ldots \ldots \ldots \ldots \ldots \ldots \ldots \ldots \ldots \ldots \ldots \ldots \ldots \ldots \ldots \ldots \ldots$

$4 T$-stress for a two-dimensional model of a crack in an infinite plate under a uniaxial tensile

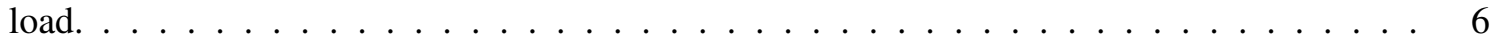




\section{ACRONYMS}

LEFM Linear Elastic Fracture Mechanics

PWR Pressurized Water Reactor

RPV Reactor Pressure Vessel 


\section{Introduction}

The Grizzly code is being developed to address aging issues in a variety of nuclear power plant systems, structures, and components. The initial application of Grizzly is to study the effects of aging in reactor pressure vessels (RPVs). RPVs that have been subjected to long-term exposure to irradiation and elevated temperatures experience embrittlement of the steel, which increases the susceptibility to fracture. To assess that, it is necessary to have both engineering fracture mechanics capabilities (to assess stress intensities at pre-existing flaws) and capabilities to model the material embrittlement process.

The Grizzly code has been enhanced to allow it to perform deterministic fracture assessments of RPVs. Development in prior years has resulted in a capability to calculate $J$-integrals, initially for 2D geometry [1], and eventually for 3D geometry [2]. For this application, these are used to calculate stress intensity factors for cracks to be used in deterministic linear elastic fracture mechanics (LEFM) assessments of fracture in degraded RPVs.

An important limitation of $J$-integrals is that they can only be used to calculate stress intensity factors for flaws subjected to pure Mode I loading, or loading normal to the crack plane. For the RPV application, this means that this capability would be limited to assessments of axis-aligned flaws. Because studying the susceptibility of off-axis flaws to fracture is an important concern, a capability to evaluate stress intensity factors for flaws subjected mixed-mode loading using interaction integrals has been developed. Interaction integrals are performed using similar computational machinery to that used for $J$-integrals, but permit the direct calculation of the Mode I, II, and III stress intensity factors. In addition to interaction integrals, the capability to evaluate the $T$-stress has been developed. This provides a measure of constraint at a crack tip, and can be used to provide an improved characterization of susceptibility to fracture.

In addition to the development and testing of these fracture techniques, benchmarking has been performed to compare deterministic fracture models run in Grizzly with models of the same flaws subjected to the same conditions in FAVOR. This tests all aspects of the thermomechanical and Mode I fracture capabilities in the Grizzly code, including the simulation of the global thermo-mechanical response of the RPV, transfer of boundary conditions to the submodel of the fracture region, the mechanical model of the fracture region, and the fracture integral evaluation capability.

To demonstrate the use of the interaction integrals on an RPV fracture application where a flaw is subjected to mixed-mode loading, flaws in RPVs with varying off-axis orientations were modeled using the same submodeling approach used for axis-aligned flaws. The interaction integral capability is used to calculate mixed-mode stress intensity factors.

In the process of doing this development and benchmarking, several other improvements were made to Grizzly. These include improvements to the handling of temperature-dependent thermal expansion coefficients, and the addition of features to extract stress profiles through the thickness of the RPV wall that will be useful in future probabilistic fracture modeling with Grizzly.

This report is organized according to these tasks. Section 2 documents the development and verification of integrals. Section 3 documents the benchmarking of Grizzly against FAVOR for axis-aligned flaws. Section 4 demonstrates the application of Grizzly to off-axis flaws. Section 5 documents other improvements made to Grizzly as part of this engineering RPV fracture mechanics capability development. Finally, Section 6 provides a summary of this work. 


\section{Interaction integrals}

The new interaction integral capability expands on the existing $J$-integral capability and provides a method for calculating mixed-mode stress intensity factors. Both methods are domain integral methods, meaning that they evaluate a contour integral around the crack tip as a volume integral over a domain around nodes along the crack. In the interaction integral method, auxiliary fields are superposed on top of the actual stress and displacement fields and using appropriate auxiliary fields the mixed-mode stress intensity factors can be derived from the integral calculation $[3,4]$. This section presents the verification of the developed interaction integral methods.

\subsection{Mode I}

The Mode I load is the opening load on a crack. To benchmark the interaction integral capability for Mode I stress intensity factors, two problems with known solutions were used: a two-dimensional problem for a through crack in an infinite plate and a semi-elliptical surface breaking crack in a semi-infinite plate. The model of a through crack in a plate has a crack width to plate width ratio of 0.0833 , and can be considered a crack in an infinite plate since a finite width correction factor derived from finite element simulations is only $0.4 \%$ [5]. The results for three contours in Table 1 show that the results are path independent and agree with the analytical solution, $K_{\mathrm{I}}=\sigma \sqrt{\pi a}$.

Table 1: Stress intensity factors for a crack in an infinite plate under a uniaxial tensile load. $K_{\mathrm{I}(0)}$ refers to a Mode I configuration in which the crack is oriented perpendicular to the applied load, while $K_{\mathrm{I}(\beta)}$ and $K_{\mathrm{II}(\beta)}$ are the Mode I and Mode II stress intensity factors, respectively, for a crack oriented at an angle $90^{\circ}-\beta$ from the applied load. The results presented are for $\beta=20^{\circ}$.

\begin{tabular}{cccccccc} 
& Contour & $K_{\mathrm{I}(0)}$ & Diff $(\%)$ & $K_{\mathrm{I}(\beta)}$ & Diff $(\%)$ & $K_{\mathrm{II}(\beta)}$ & Diff $(\%)$ \\
\hline 2D & 1 & 280.6466 & 0.1 & 247.9932 & 0.2 & -90.04638 & 0.03 \\
2D & 2 & 280.6882 & 0.2 & 247.9504 & 0.2 & -89.92416 & 0.2 \\
2D & 3 & 281.0460 & 0.3 & 248.0082 & 0.2 & -90.07147 & 0.01 \\
\hline 3D & 1 & 281.7527 & 0.5 & 249.0504 & 0.6 & -90.36735 & 0.3 \\
3D & 2 & 281.5965 & 0.5 & 248.8453 & 0.6 & -90.18858 & 0.1 \\
3D & 3 & 281.7548 & 0.5 & 248.7261 & 0.5 & -90.31409 & 0.3
\end{tabular}

The mesh representing a semi-elliptical flaw is shown in Fig. 1. Results for $K_{\mathrm{I}}$ using the Grizzly interaction integral as well as the $J$-integral capability are compared in Fig. 2 with an empirical equation [6] fit to finite-element simulations by Newman and Raju. The position $\phi=0^{\circ}$ is at the free surface and $\phi=90^{\circ}$ is at the symmetry plane. Benthem [7] showed that for a crack that intersects a surface at a right angle, the stress intensity factor is zero at the surface. Since the $K_{\mathrm{I}}$ values at a node represents an average over a segment of the crack front, the value at the surface will be unreliable and has been omitted from Fig. 2. In general, the results agree well with the reference also for a curved crack.

\subsection{Mode II}

The Mode II load is the shear stress acting parallel to the plane of the crack. The Mode II stress intensity factors were verified using an angled crack in an infinite plate under uniaxial tension. For a crack oriented $90^{\circ}-\beta$ from the applied normal stress, the Mode I and Mode II stress intensity factors are given by

$$
\begin{aligned}
K_{\mathrm{I}} & =K_{\mathrm{I}(0)} \cos ^{2} \beta \\
K_{\mathrm{II}} & =K_{\mathrm{I}(0)} \cos \beta \sin \beta
\end{aligned}
$$




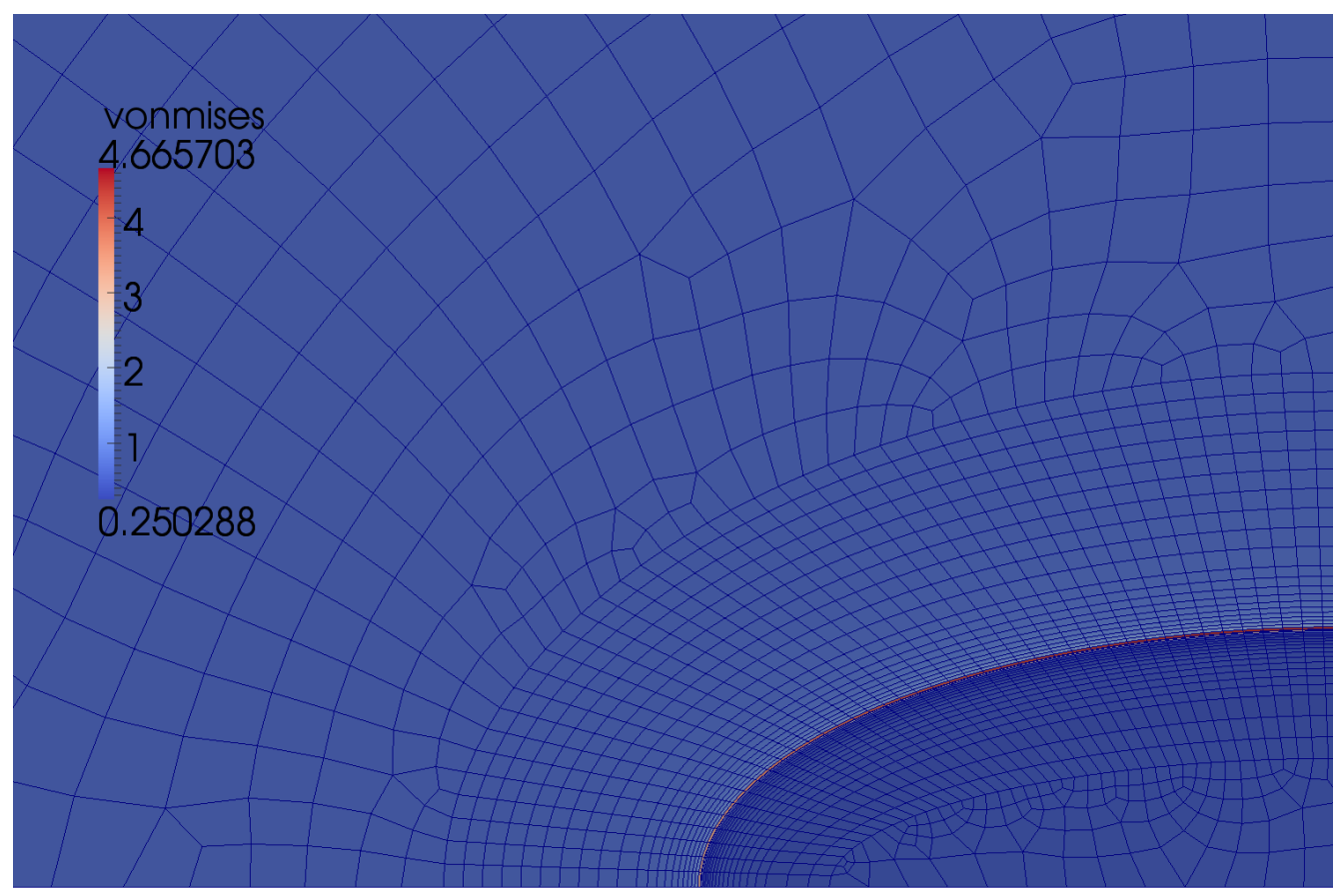

Figure 1: Closeup showing the crack front region of the elliptical flaw mesh. The bottom edge is a free surface $\left(\phi=0^{\circ}\right)$ and the right hand edge is a symmetry plane $\left(\phi=90^{\circ}\right)$.

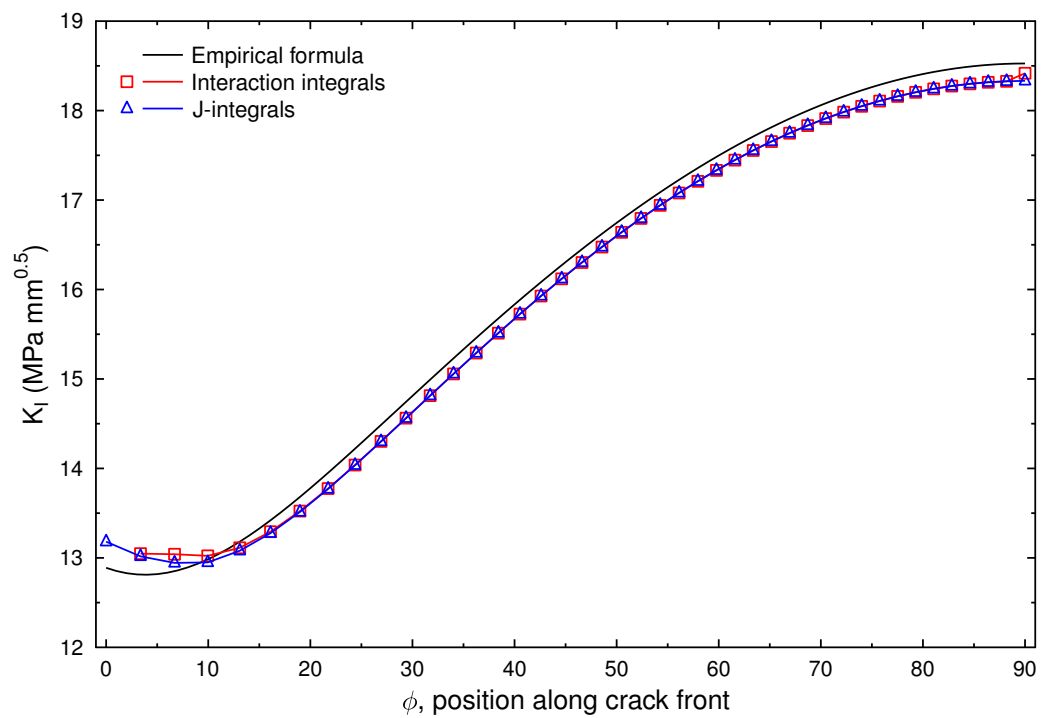

Figure 2: Mode I stress intensity factor along the crack front of a semi-elliptical surface-breaking flaw compared with an empirical formula by Newman and Raju [6]. 


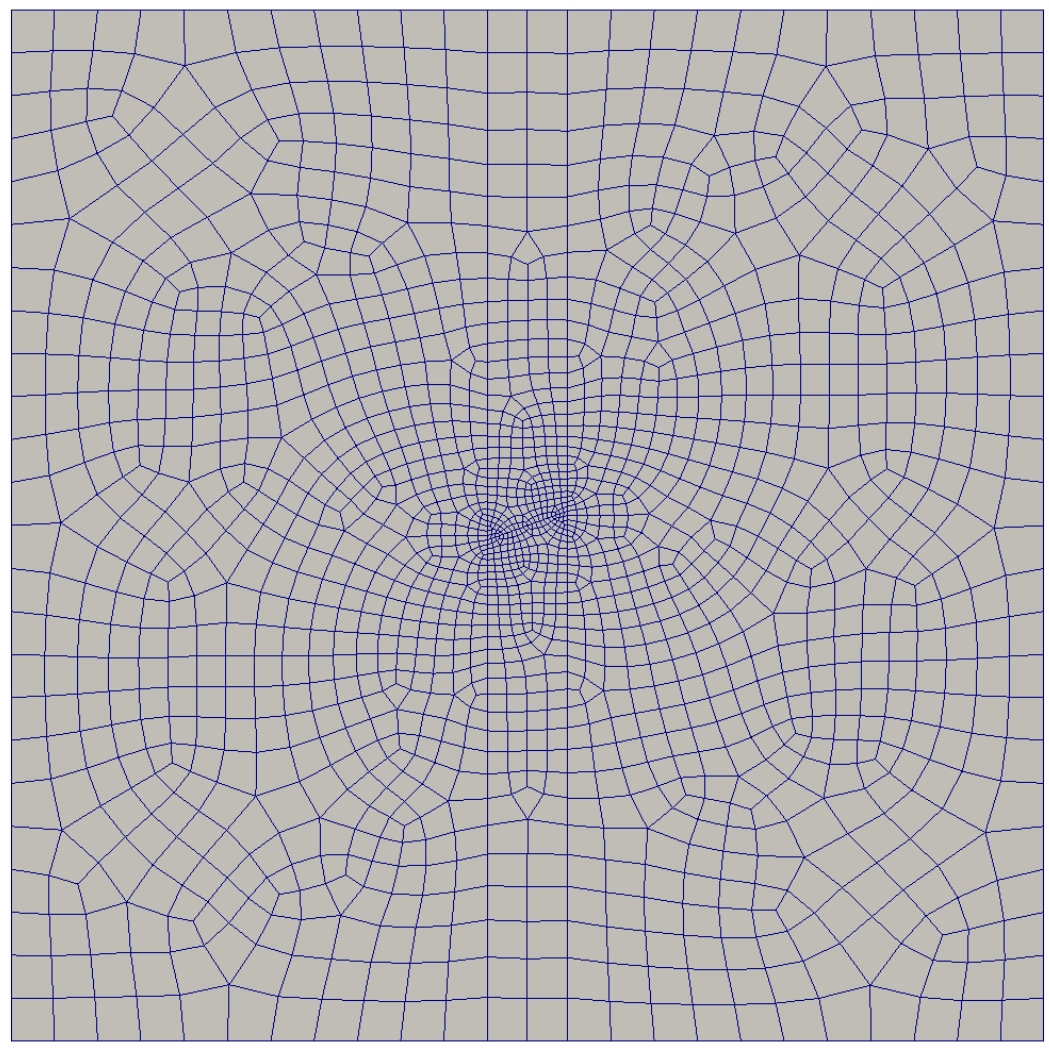

Figure 3: Two-dimensional model of an angled through crack in an infinite plate. The crack width to plate width ratio is 0.0833 . The crack is oriented at an angle $\beta=20^{\circ}$ from the applied normal stress.

where $K_{\mathrm{I}(0)}=\sigma \sqrt{\pi a}$ is the Mode I stress intensity factor for a crack oriented perpendicular to the applied stress $(\beta=0)$. When $\beta=0$, the load on the crack is pure Mode I loading and $K_{\mathrm{II}}=0$. The finite element model used is shown in Fig. 3 and has orientation $\beta=20^{\circ}$. The model has a crack width to side length ratio of 0.0833 and approximates a crack in an infinite plate. Two-dimensional and extruded three-dimensional models were used and the results from the Grizzly calculation are presented in Table 1. The difference between the Grizzly results and the analytical solution is less than $1 \%$ for all cases.

\subsection{Mode III}

The Mode III load is the out-of-plane shear stress on, or tearing of, the crack. The Mode III stress intensity factors were tested using a penny-shaped crack in a cylinder under torsion. For a crack of radius $a$ in a cylinder of radius $b$, where $(a / b \rightarrow 0)$, and with an applied torque $T$, an asymptotic solution to the Mode III stress intensity factor is given by [8]

$$
K_{\mathrm{III}}=\frac{4}{3 \pi} \frac{2 T a}{\pi b^{4}} \sqrt{\pi a} .
$$

The finite element model has a crack with radius $a=5$ and cylinder radius $b=50$ and is composed of 129,920 8-noded brick elements. The crack tip is sharp. Fig. 4 shows a cross section of the model. The material is assigned a Young's modulus of 207,000 and a Poisson's ratio of 0.3. Table 2 shows results for $K_{\mathrm{III}}$ at the crack tip when a displacement about the center axis, corresponding to a torque of $26,934,960$, is applied to the ends of the cylinder. Grizzly predicts stress intensity factors in good agreement with theory. 
Table 2: Mode III stress intensity factor for a 3D model of penny-shaped crack in cylinder under torsion.

\begin{tabular}{lccc} 
Contour & Asymptotic solution & Grizzly & Difference $(\%)$ \\
\hline 1 & & 22.9977 & 0.3 \\
2 & 23.0747 & 22.9955 & 0.3 \\
3 & & 22.9939 & 0.4
\end{tabular}
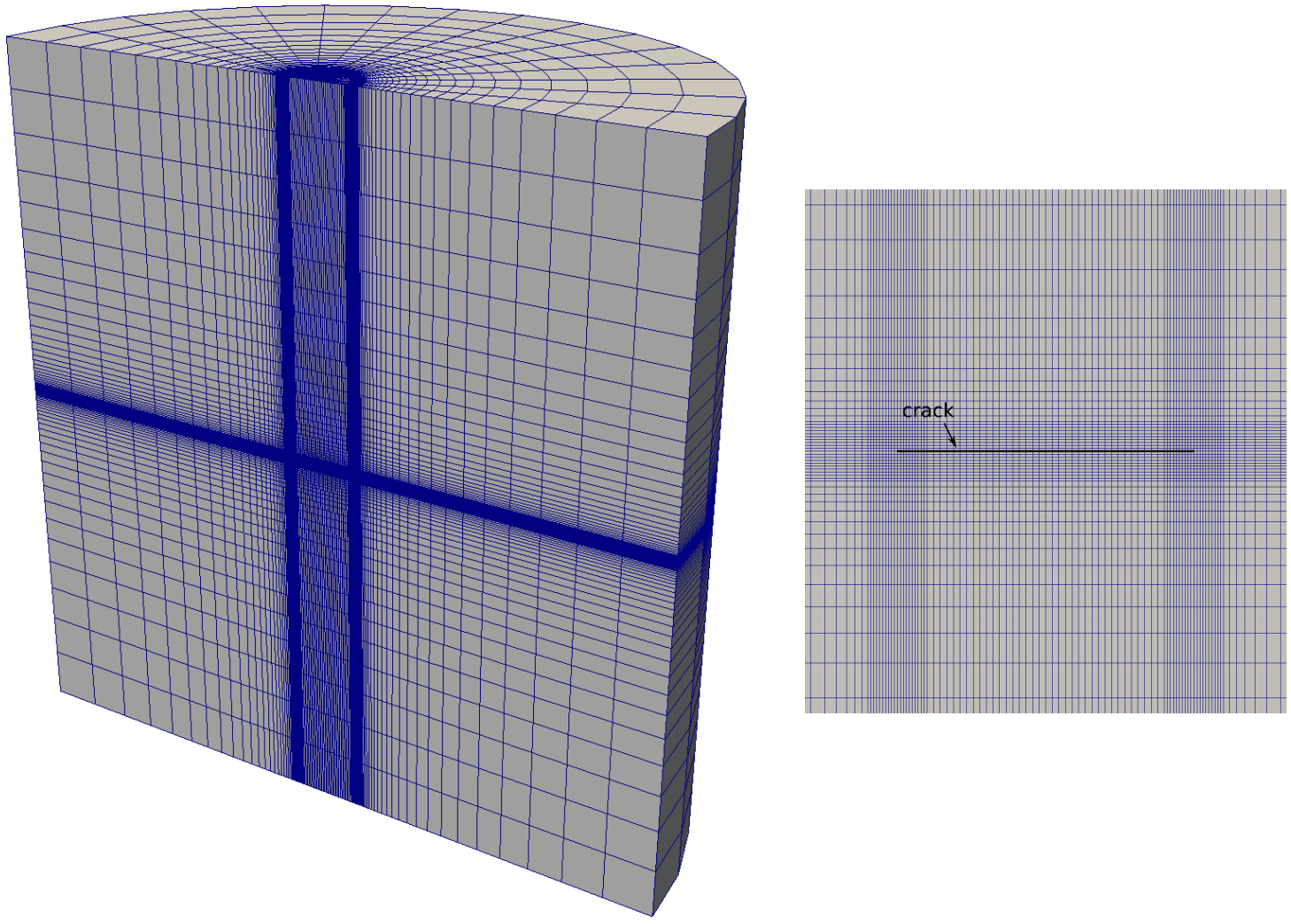

Figure 4: Cross section of cylinder model with a penny-shaped crack. In the right hand figure, the crack position is illustrated by a black line. The actual crack is sharp and the crack face separation distance is virtually zero.

\subsection{Mixed-mode loading}

Finally, all three modes were tested together, using a model of a $360^{\circ}$ sector around a sharp crack tip (Fig. 5). For this problem, displacements were prescribed according to Williams' analytical solution for the displacement field around a crack tip for stress intensity factors $K_{\mathrm{I}}=K_{\mathrm{II}}=K_{\mathrm{III}}=1.0$ and, hence, we expect the interaction integral analysis to return the same stress intensity factors. The results are presented in Table 3 and the good agreement gives confidence that the interaction integrals can be used for mixed-mode loading.

\section{$2.5 \quad T$-stress}

The $T$-stress is the first second-order parameter in Williams expansion of stress at a crack tip and is a constant stress parallel to the crack. Contrary to $J, T$-stress depends on geometry and size and can give a more accurate description of the stresses and strains around a crack tip than $J$ alone. The $T$-stress characterizes the crack-tip 


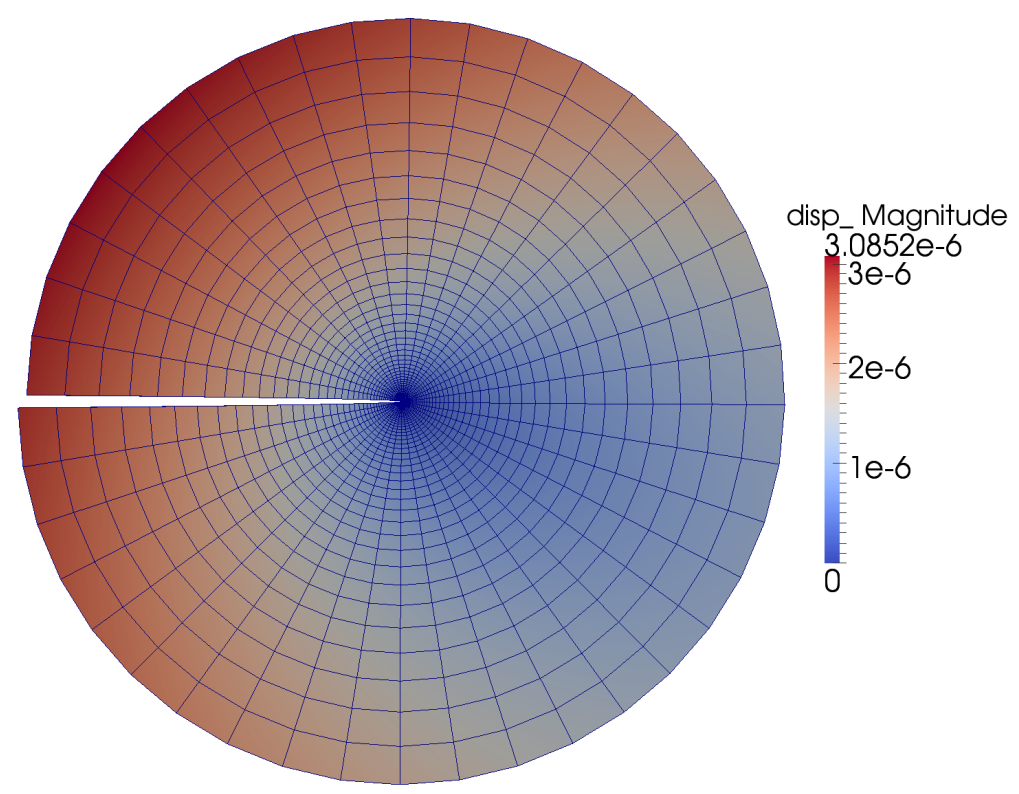

Figure 5: Mesh representing a $360^{\circ}$ sector around a crack tip. The displacements of the nodes are scaled up by a factor $10^{5}$ to show the crack opening.

Table 3: Stress intensity factors for $360^{\circ}$ model of crack front with displacements corresponding to $K_{\mathrm{I}}=$ $K_{\mathrm{II}}=K_{\mathrm{III}}=1.0$.

\begin{tabular}{lccc} 
Contour & $K_{\mathrm{I}}$ & $K_{\mathrm{II}}$ & $K_{\mathrm{III}}$ \\
\hline 1 & 1.00266 & 1.00207 & 1.00100 \\
2 & 1.00261 & 1.00195 & 1.00101 \\
3 & 1.00259 & 1.00191 & 1.00102
\end{tabular}

constraint and a negative $T$-stress is associated with loss of constraint and a higher fracture toughness than would be predicted from a one-parameter $J$ description of the load on the crack. $T$-stresses can be calculated with the interaction integral methodology described in section 2, using appropriate auxiliary fields [9]. The new capability was verified with two-dimensional and three-dimensional crack front models.

For a crack in an infinite plate under a uniaxial tensile load, the $T$-stress has the exact solution $T=-\sigma^{\infty}$ [10]. The results are presented in Table 4 and show path independence and are in excellent agreement with the analytical solution.

To verify that the $T$-stress solutions are correct also for three-dimensional problems, a penny-shaped crack under tensile loading was simulated. In Fig. 6 Grizzly results for the $T$-stress are plotted and compared with the analytical solution $T(\phi)=-\frac{1+2 v}{2} \sigma^{\infty}$ given by Wang [11]. There is good agreement except towards the two symmetry planes, where there still is an issue to be resolved.

Table 4: $T$-stress for a two-dimensional model of a crack in an infinite plate under a uniaxial tensile load.

\begin{tabular}{lccc} 
& $0.06<\mathrm{r}<0.08$ & $0.08<\mathrm{r}<0.10$ & $0.10<\mathrm{r}<0.12$ \\
\hline Analytical solution & & -100.00 & \\
Grizzly simulation & -99.9442 & -99.9514 & -99.9590 \\
Difference (\%) & 0.06 & 0.05 & 0.04
\end{tabular}




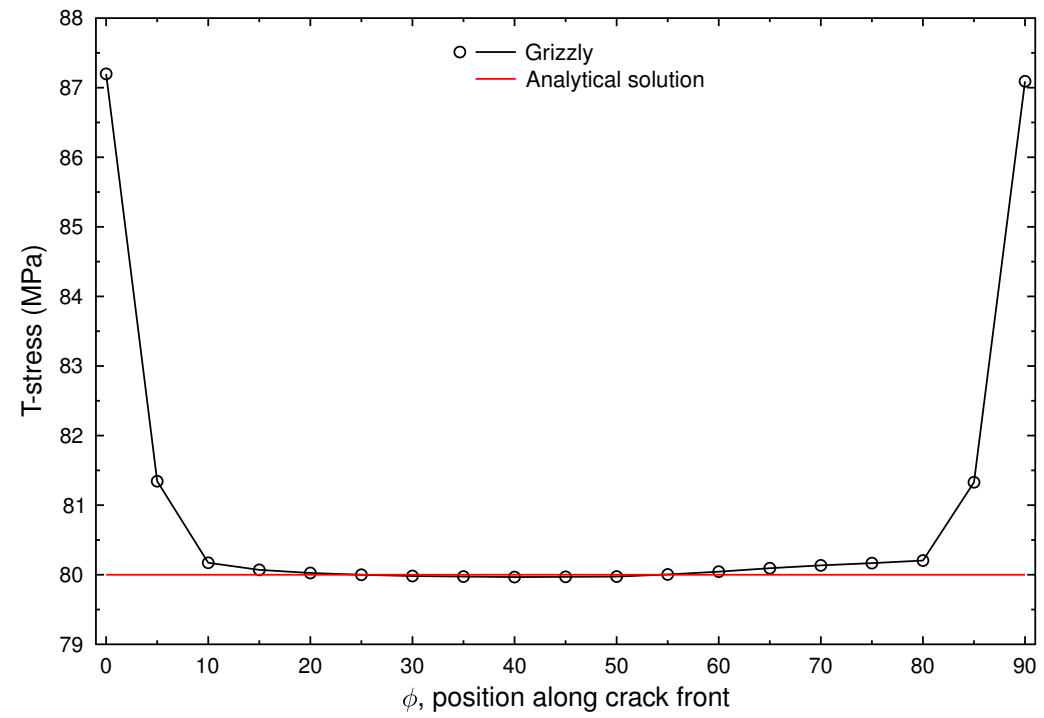

Figure 6: $T$-stress along the crack front of a penny-shaped crack under tension calculated with Grizzly and compared with analytical solution. 


\section{Benchmarking of axis-aligned flaw models with FAVOR}

Initial verification problems of the fracture mechanics capabilities in Grizzly have been developed, run and compared against analytical solutions for a variety of problems. This report, as well as previous milestone reports on Grizzly development, include documentation of these problems. Verification problems of individual capabilities are extremely important to gain confidence in any simulation code. It is only through such testing of individual capabilities that confidence can be gained in an analysis that combines those capabilities.

The fracture verification problems that have been run with Grizzly typically involve simple geometries subjected to simple loading. To gain confidence in the method used for analyzing the global RPV response, transferring results to a submodel, and performing a fracture analysis on the submodel, an initial benchmarking study has been performed to compare results from Grizzly with results from another code. Code-to-code comparisons do not constitute verification or validation of a code, but they do provide some confidence that algorithms are implemented correctly, or at least that consistent assumptions were made in both codes.

The FAVOR code $[12,13]$ is purpose-developed for probabilistic fracture mechanics analysis of reactor pressure vessels, although it can be used for both probabilistic and deterministic analysis. Because of the extensive efforts that have gone into its development and testing, it is expected to give reliable solutions for comparison. Grizzly results have been compared with comparable FAVOR simulation results, and are presented here.

FAVOR computes the global thermomechanical response of the RPV using a 1D representation of the through-thickness behavior in the beltline region, where embrittlement is most severe. FAVOR performs polynomial least squares fits on stress profiles through the thickness of the wall, and the coefficients of those fits are used as influence coefficients for a library of solutions derived from detailed 3D fracture models.

Figure 7 shows the meshes used to model the global response and flaw regions in Grizzly. A full 3D model is used to represent the RPV, but in this study, the flaw is located in the middle of the beltline region, and uniform pressure and temperature conditions are applied to the entire inner surface of the RPV. The response in this region is thus axisymmetric, so the 3D Grizzly model is equivalent to the 1D FAVOR model in this case.
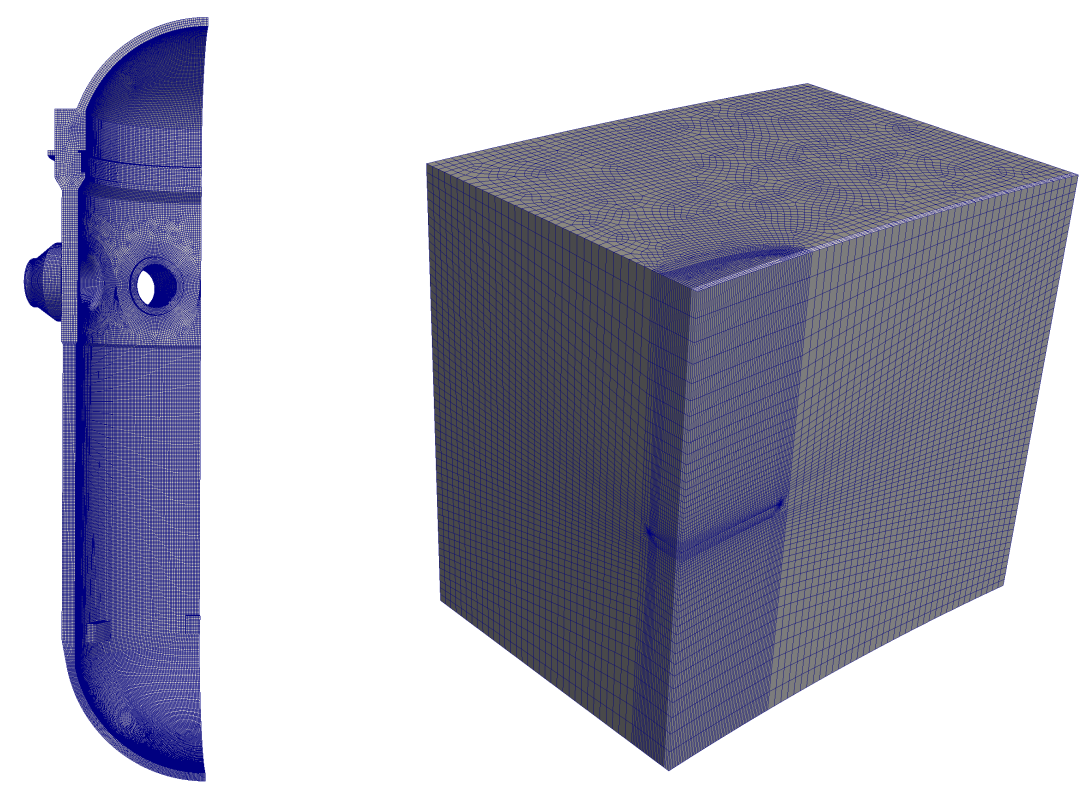

Figure 7: Meshes used for global RPV model (left) and local model of surface-breaking circumferential flaw region (right) 
The global RPV model for this study was developed to be representative of that of a typical pressurized water reactor (PWR), but does not represent a specific reactor. The overall wall thickness in the beltline region is $8.623 \mathrm{in}$, including the cladding, which has a thickness of $0.16 \mathrm{in}$. The inner radius is $86.5 \mathrm{in}$. The flaw modeled is a surface-breaking elliptic flaw aligned in the circumferential direction, per FAVOR nomenclature. Note that this differs from the naming convention used in prior Grizzly milestone reports. The flaw has a depth of 1 inch, and an aspect ratio of 6 , meaning that the major radius is 3 times the minor radius.

The RPV models were subjected to a transient using the time histories of coolant temperature and pressure shown in Figure 8. Fracture domain integrals were evaluated along the crack front in the submodel using three different rings. The domain integrals evaluated consisted of the $J$-integral and Mode I interaction integral. Figure 9 shows the time histories of the Mode I stress intensity factor evaluated using these two integrals. The interaction integral directly provides the stress intensity factor, while the stress intensity is evaluated from the $J$-integral using the standard formula for plane strain conditions.

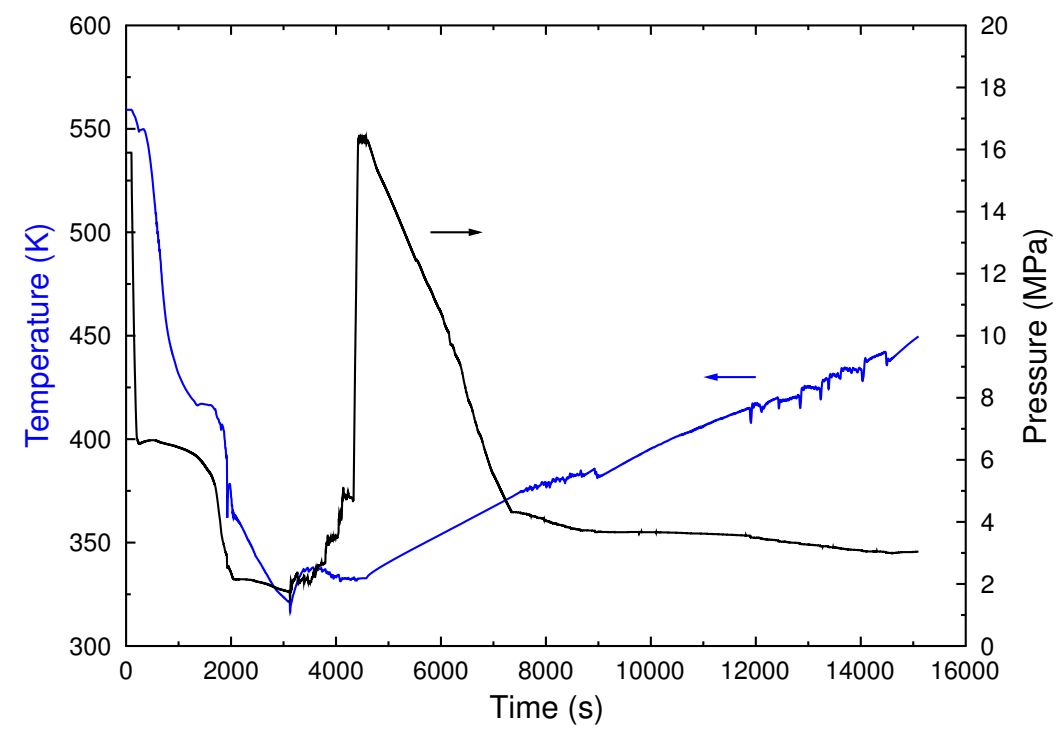

Figure 8: Time histories of coolant temperature and pressure applied to RPV

The $J$-integrals for the three rings were nearly identical to each other, as were the interaction integrals for those rings, and the results shown in Figure 9 are for the first ring. As can be seen from that plot, early in the transient event, when the stress intensity is near its peak, the stress intensity calculated with Grizzly using the interaction integral is nearly identical to that calculated by Grizzly using the $J$-integral, but the two diverge later on in the analysis. The Grizzly results have approximately the same shape as the FAVOR results early in time, although the Grizzly results are 5-10\% lower than the FAVOR results. Late in time, the Grizzly interaction integral follows the FAVOR result quite closely. Investigation into the cause of these discrepancies is ongoing, as the interaction integral and $J$-integral should produce nearly identical results. 


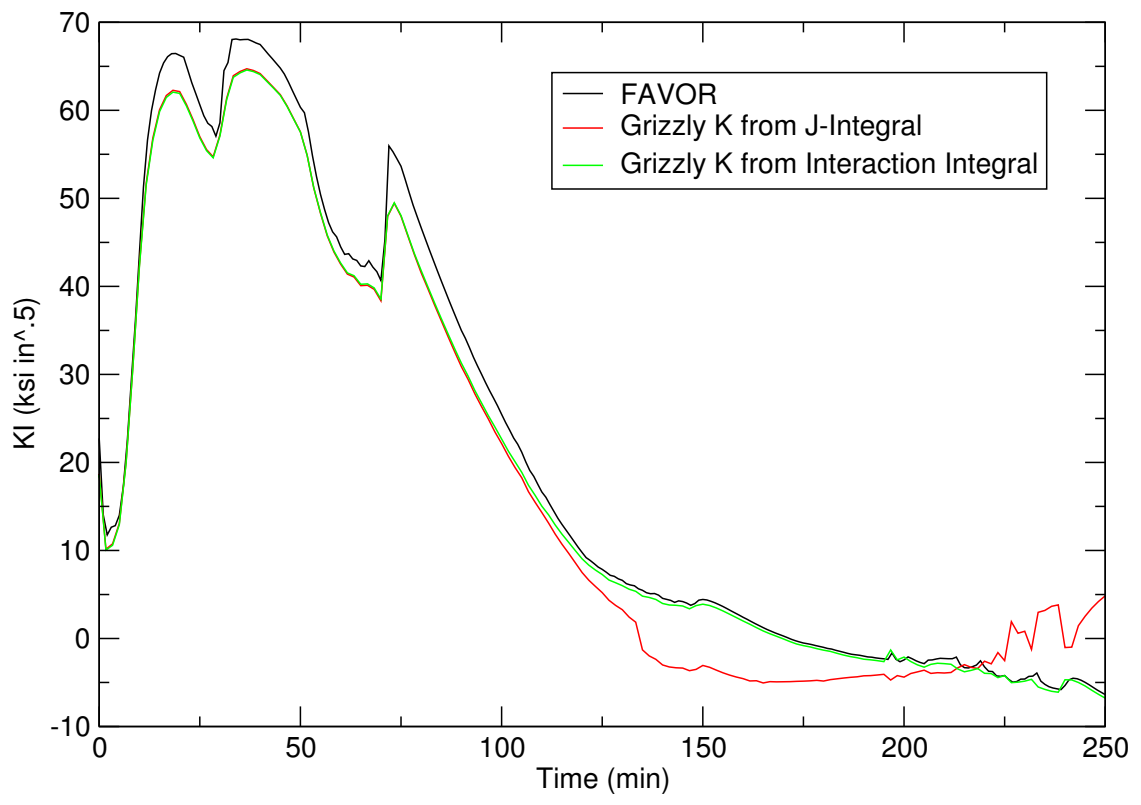

Figure 9: Comparison of time histories of $K_{\mathrm{I}}$ between Grizzly and FAVOR 


\section{Analysis of off-axis flaws}

One of the motivations for developing the capability to evaluate interaction integrals in Grizzly is to enable the evaluation of mixed-mode stress intensity factors for flaws oriented off-axis. To demonstrate the application of this capability, a demonstration study on flaws with lamellar (flaw normal is normal to radial direction) orientation and rotated 10 degrees and 15 degrees from that orientation. Figure 10 shows a schematic of these flaw orientations and cross-sections of the finite element meshes used to represent the region in the vicinity of the crack in the submodels. These flaws are all circular (penny-shaped) embedded flaws with the same flaw radius, which is $0.197 \mathrm{in}$. The center of the flaw in all cases is located at a depth of 4.05 in from the inner wetted surface of the RPV.

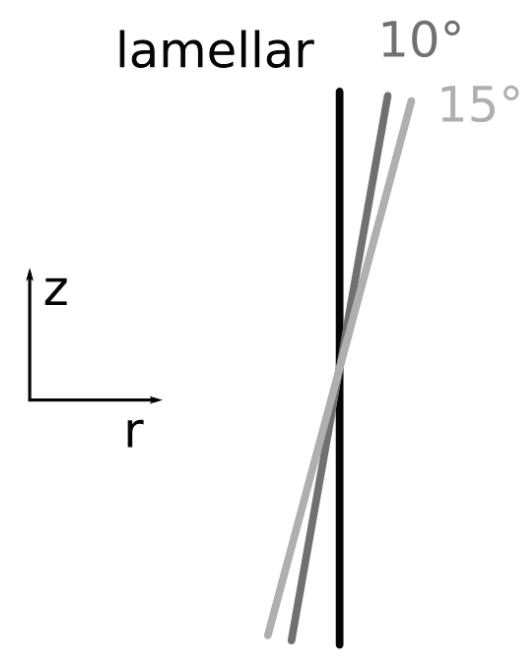

(a)

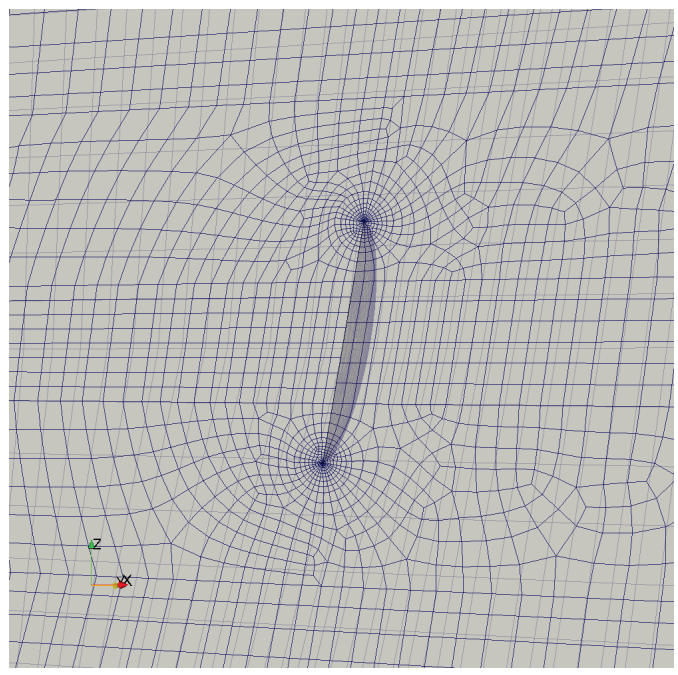

(c)

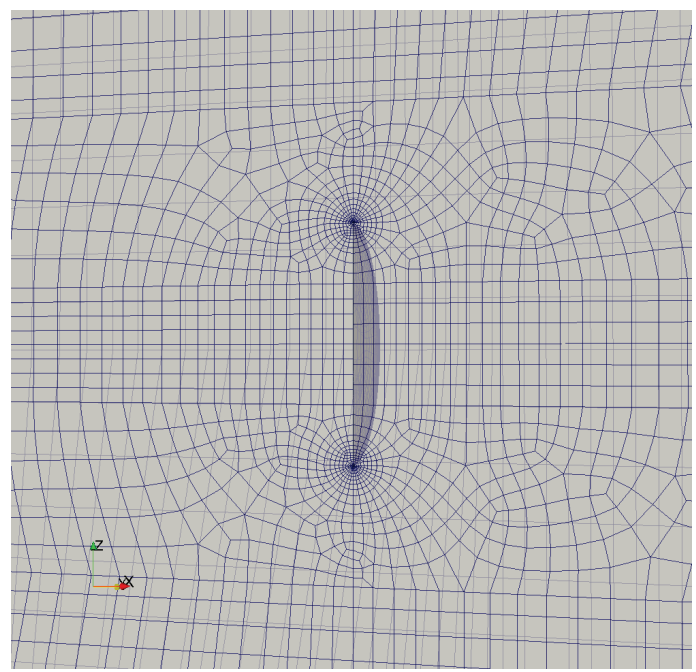

(b)

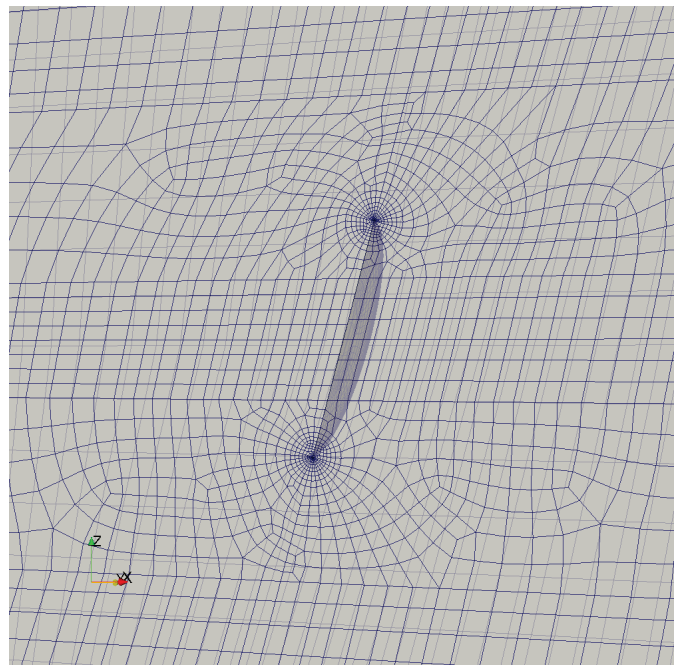

(d)

Figure 10: Cross section of the crack region of meshes representing penny-shaped flaws that are (b) lamellar or off-axis by an angle (c) $10^{\circ}$ or (d) $15^{\circ}$. The $z$ axis is parallel to the centerline of the pressure vessel.

This model was used together with the global RPV model used in Section 3, and subjected to the same loading conditions. Mode I, II, and III stress intensity factors were calculated using interaction integrals with three different ring radii in Grizzly. All three rings gave very similar results, and results for only the smallest 
ring are presented here.

Figure 11 shows the time history of the Mode I stress intensity factor for the three flaw orientations. These are reported at three locations around the circumference of the flaw: at the top ( 0 degrees), middle (90 degrees), and bottom (180 degrees). Rotating the flaw away from the lamellar (0 degree) orientation results in a decrease in the Mode I stress intensity.

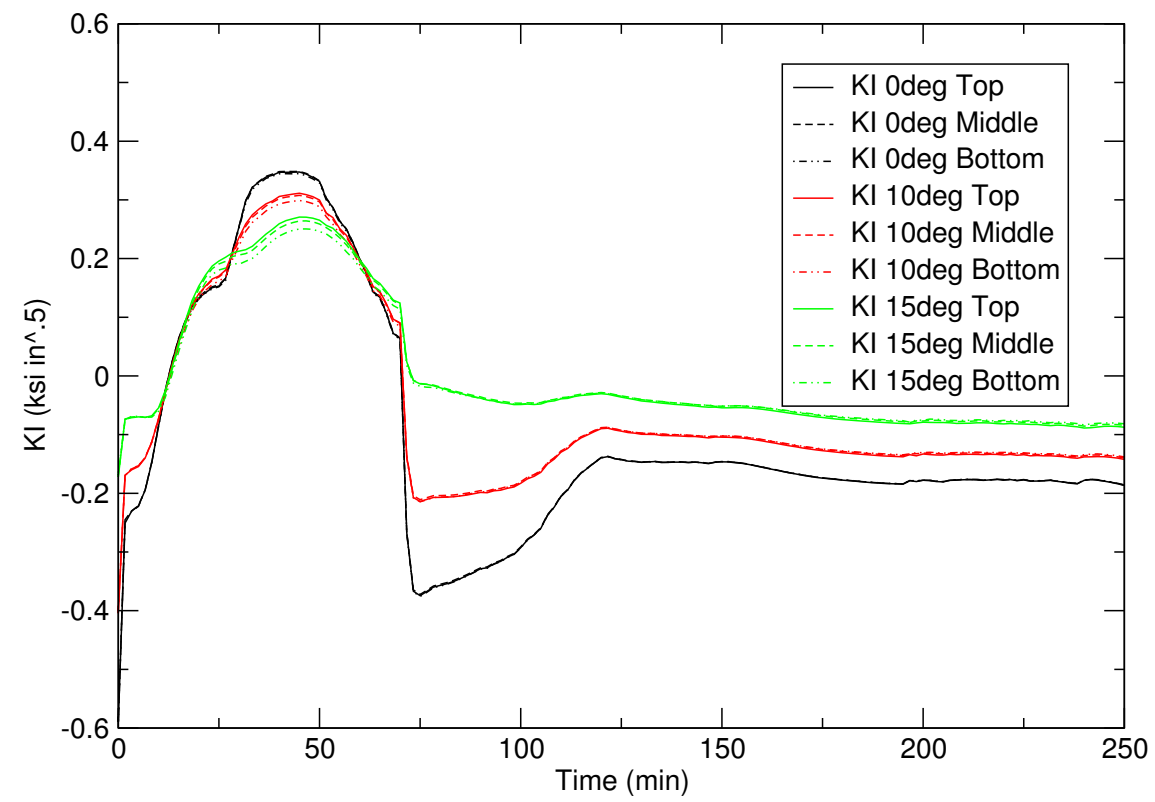

Figure 11: Time histories of Mode I stress intensity factors for various locations on flaws oriented at 0,10 , and 15 degrees off-axis.

Figure 12 and 13 show the Mode II and III stress intensity factor histories for the same flaw orientations and locations on those flaws. As expected, these are quite low for the lamellar orientation, and increase significantly as the cracks are rotated away from that orientation.

These are initial results demonstrating the use of this capability. Further work will be performed to assess the effects of flaw geometry, orientation, and loading conditions on these results, and to assess the susceptibility of such flaws to fracture. 


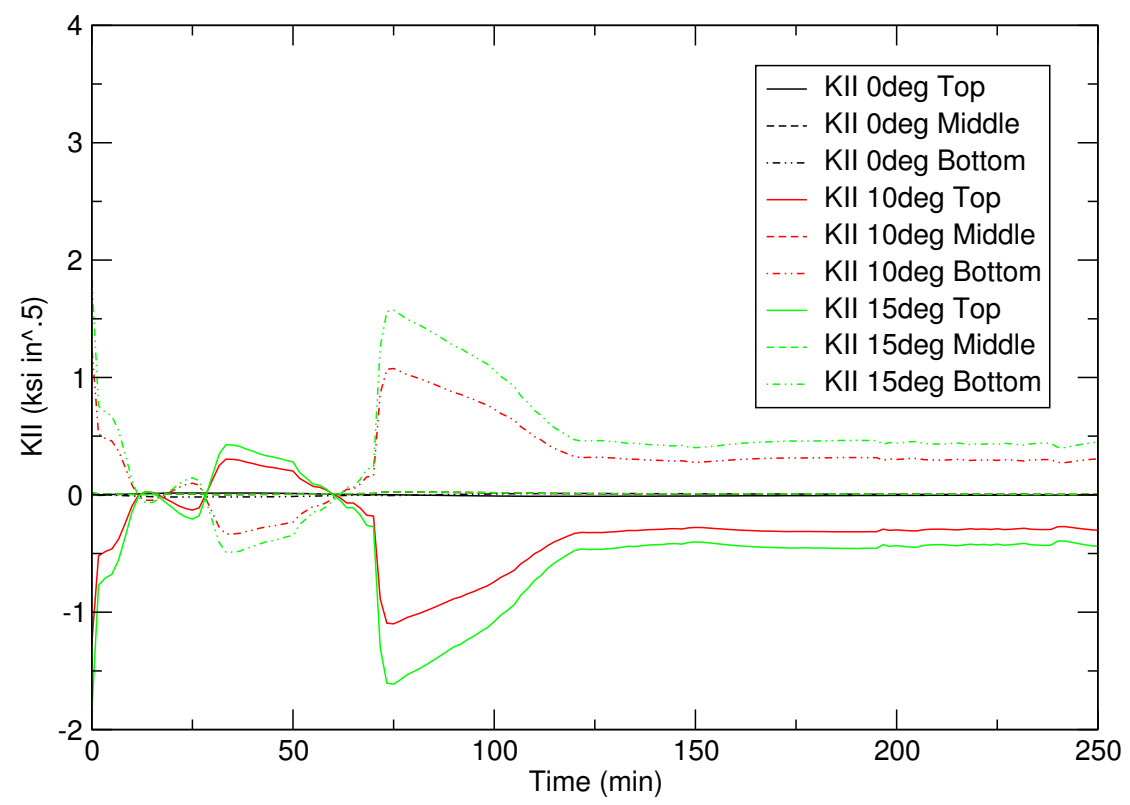

Figure 12: Time histories of Mode II stress intensity factors for various locations on flaws oriented at 0, 10, and 15 degrees off-axis.

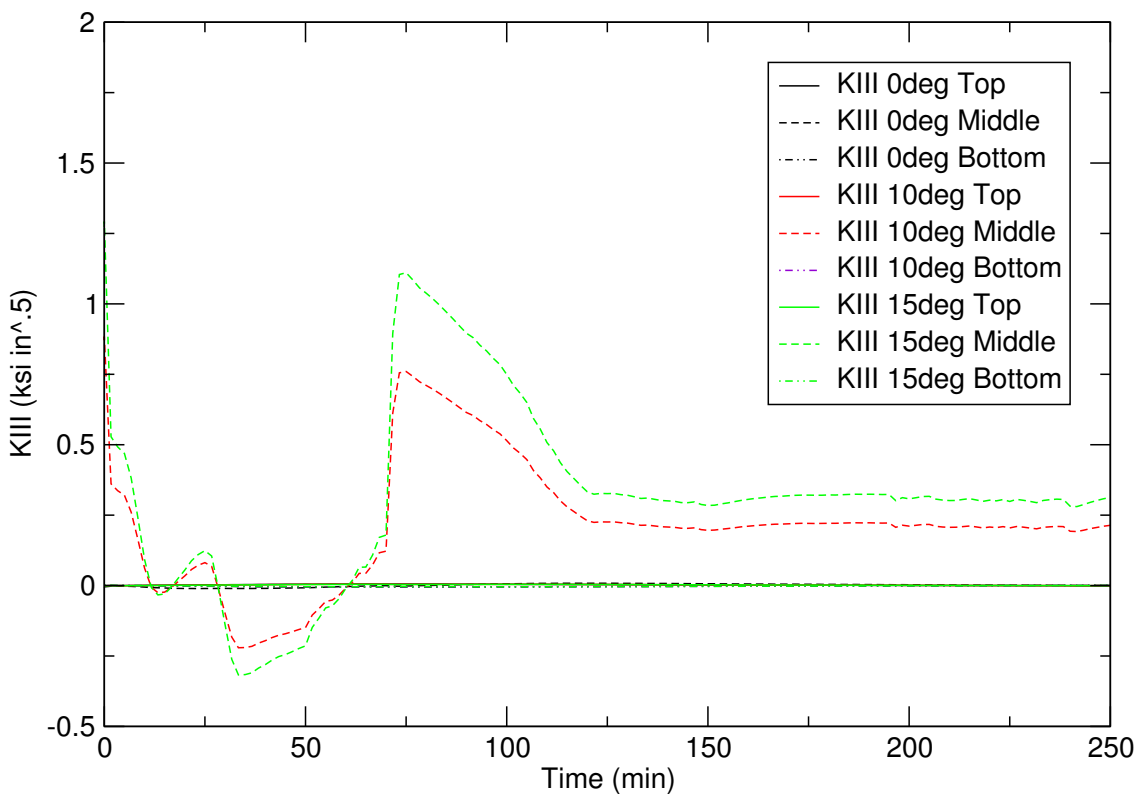

Figure 13: Time histories of Mode III stress intensity factors for various locations on flaws oriented at 0, 10, and 15 degrees off-axis. 


\section{Other Code Enhancements}

In addition to the fracture integral capabilities documented in prior sections, other improvements were made to Grizzly to enable it to properly model the thermo-mechanical response of RPVs, and to enable future use of Grizzly for probabilistic fracture modeling.

\subsection{Temperature-dependent thermal expansion}

Both the base metal and the liner in RPVs have temperature-dependent elastic properties and thermal expansion coefficients. The thermal expansion coefficient can be specified as an instantaneous thermal expansion coefficient, which defines the thermal strain increment under an infinitesimal change in the temperature. Using the notation of [14], for an isotropic material, this instantaneous thermal expansion coefficient at a given temperature, $T$ is referred to as $\alpha_{(T)}$, and the instantaneous thermal strain, $\epsilon^{\text {th }}$ is defined as:

$$
\mathrm{d} \epsilon^{t h}=\alpha_{(T)} \mathrm{d} T .
$$

Alternatively, the thermal expansion can be expressed as a total thermal strain, $\bar{\alpha}_{(T)}$ at a given temperature relative to the strain at a reference temperature, $T_{r e f}$ :

$$
\bar{\alpha}_{(T)}=\frac{1}{\left(T-T_{r e f}\right)} \int_{T_{r e f}}^{T} \alpha_{(T)} \mathrm{d} T
$$

Because total thermal expansion can be readily measured experimentally, it is common to express thermal expansion for materials in this manner, as is the case for RPV materials.

Grizzly previously permitted the use of materials with temperature-dependent thermal expansion coefficients, but only if the data was provided in the form of instantaneous coefficients. To permit the use of data in its most available form and facilitate comparisons with other codes, Grizzly has been extended to permit temperature-dependent thermal expansion data to be provided in either format. If the data is provided in the mean form, a reference temperature must be specified, and it does not need to coincide with the stress-free temperature. The method outlined in [14] is employed to calculate the incremental thermal strain when the reference and stress-free temperatures differ. Regression tests have been developed to demonstrate that these two methods produce the same results for equivalent mean and instantaneous thermal expansion functions, including usage with fracture integrals.

\subsection{Stress profile extraction}

For the fracture demonstrations performed here, global displacement and temperature profiles are transferred to the submodels and used as boundary conditions. This procedure has been demonstrated to work well. To enable the use of Grizzly for probabilistic fracture mechanics evaluations, it will be necessary to represent the fracture response using a reduced-order model that takes a small number of parameters. The FAVOR code represents the stress profile in the global model using least-squares fits of the through-wall stress profile. This permits the usage of a small number of parameters to represent the global response, which are used as influence coefficients for archived fracture mechanics solutions. These can be used in a similar manner to characterize the global response using a small number of parameters that can be used to define the loading on a reduced order model that represents the response of a detailed Grizzly fracture submodel.

To enable Grizzly to be used to calculate and characterize the global response using a small number of parameters, a capability has been developed to output the stress profile for a set of finite elements that fall on a line through a solid model. The user defines the end points of the line, and the stresses can be output as 
integration point quantities projected to the position along that line, and least-square fits using polynomials of arbitrary order can be performed using this data.

Figure 14 shows a demonstration of the usage of this capability. A user-defined line passes radially from the inner to outer surface of the 3D RPV model used for other demonstrations in this report. Integration point stresses are output and projected along this line. A linear least-squares fit is performed to characterize the stress profile through the cladding, while a least-squares fit using a cubic polynomial is performed on the stresses through the base material. Samples are taken of the fitted polynomial function and plotted together with the integration point data.

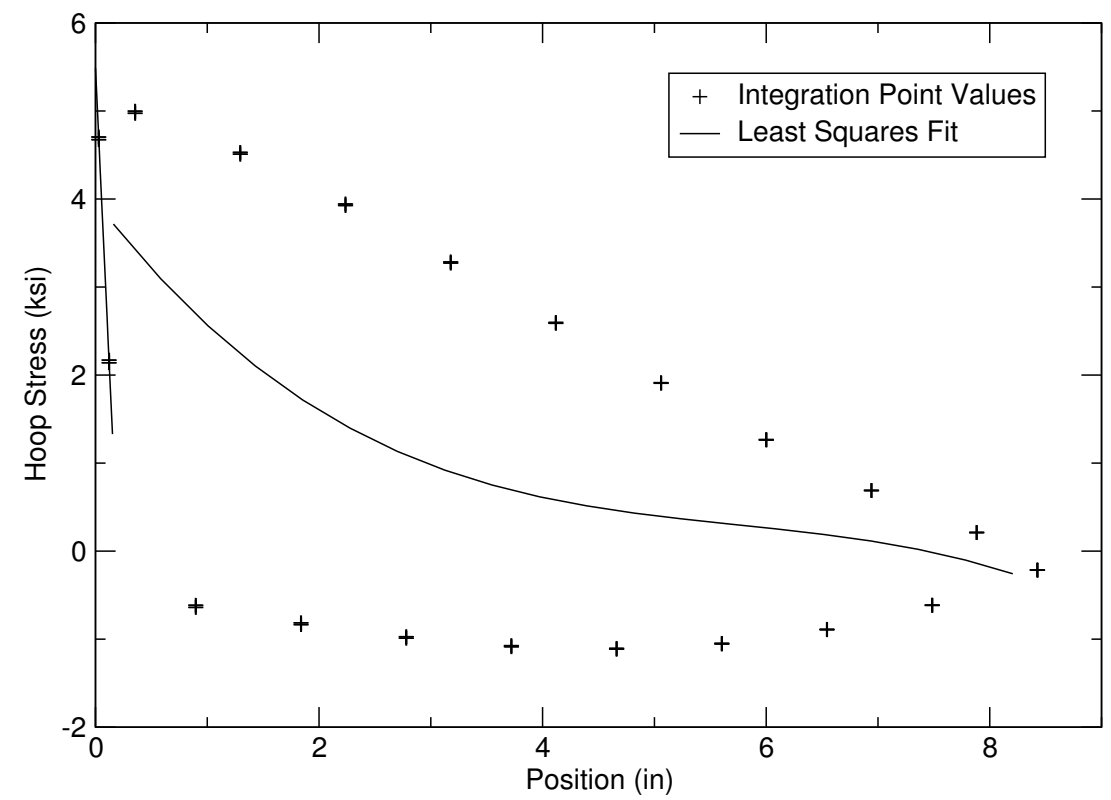

Figure 14: Through-wall stress profile for RPV 73 minutes into transient event, showing stresses at integration points and linear and cubic least-squares fit of stress profile for cladding and base metal. 


\section{Summary}

This report documents the development, testing, and application of capabilities in the Grizzly code to enable the study of flaws in RPVs that are subjected to mixed-mode loading, such as what would be experienced by a flaw oriented off-axis. Capabilities have been developed to evaluate mixed-mode stress intensity factors using interaction integrals and to evaluate the $T$-stress. These have been tested on problems with known solutions and shown to produce good matches with those solutions. There are some issues with the $T$-stress near free surfaces, and those are being investigated.

The approach for evaluating stress intensity factors in Grizzly using a combination of a global model for the thermomechanical response of the RPV and a local model for the mechanical response of the flaw region has been benchmarked against the FAVOR code for an axis-aligned flaw. The interaction integral reasonably replicates the FAVOR response throughout a representative transient event, although it does underpredict the stress intensity by $5-10 \%$. The $J$-integral produced results that were nearly identical to the interaction integral early in the event, but then diverged. These discrepancies are currently being investigated.

Results were shown for an initial demonstration of the usage of Grizzly to evaluate mixed-mode stress intensity factors on a lamellar flaw and on that same flaw geometry inclined at two angles off-axis. Future work will investigate the sensitivity of these results to flaw geometry and loading conditions.

Finally, a brief description of other enhancements made to Grizzly in support of this work was provided. These include options on ways to define temperature-dependent thermal expansion coefficients, as well as a feature to extract through-wall stress profiles and perform least-squares fits on the stresses. This will be used in the future to facilitate the usage of Grizzly to generate and use reduced order models to represent stress intensity in probabilistic fracture mechanics assessments of RPVs. 


\section{References}

1. Stephen R. Novascone, Benjamin W. Spencer, and Jason D. Hales. Status report on the Grizzly code enhancements. INL/EXT-13-30315, Idaho National Laboratory, Idaho Falls, ID, September 2013.

2. Benjamin Spencer, Marie Backman, Pritam Chakraborty, and William Hoffman. 3D J-integral capability in Grizzly. INL/EXT-14-33257, Idaho National Laboratory, Idaho Falls, ID, September 2014.

3. M. Stern, E.B. Becker, and R.S. Dunham. A contour integral computation of mixed-mode stress intensity factors. International Journal of Fracture, 12(3):359-368, 1976.

4. J. F. Yau, S. S. Wang, and H. T. Corten. A Mixed-Mode Crack Analysis of Isotropic Solids Using Conservation Laws of Elasticity. Journal of Applied Mechanics, 47(2):335, 1980.

5. Hiroshi Tada. The stress analysis of cracks handbook. ASME Press, New York, 3rd ed edition, 2000.

6. J.C. Newman and I.S. Raju. An empirical stress-intensity factor equation for the surface crack. Engineering Fracture Mechanics, 15(1-2):185-192, January 1981.

7. J.P. Benthem. State of stress at the vertex of a quarter-infinite crack in a half-space. International Journal of Solids and Structures, 13(5):479-492, January 1977.

8. J.P. Benthem and W. T. Koiter. Methods of analysis and solutions of crack problems. Recent developments in fracture mechanics, chapter Asymptotic approximations to crack problems. Number v. 1 in Mechanics of fracture. Noordhoff International Pub, Leyden, 1973.

9. Toshio Nakamura and David M. Parks. Determination of elastic t-stress along three-dimensional crack fronts using an interaction integral. International Journal of Solids and Structures, 29(13):1597-1611, January 1992.

10. T. L. Anderson. Fracture mechanics: fundamentals and applications. Taylor \& Francis, Boca Raton, FL, 3rd ed edition, 2005.

11. Xin Wang. Elastic T-stress solutions for penny-shaped cracks under tension and bending. Engineering Fracture Mechanics, 71(16-17):2283-2298, November 2004.

12. T.L. Dickson, P. T. Williams, and S. Yin. Fracture Analysis of Vessels - Oak Ridge, FAVOR, v12.1, computer code: User's guide. ORNL/TM-2012/566, USNRC Adams number ML13008A016, Oak Ridge National Laboratory, Oak Ridge, TN, November 2012.

13. P.T. Williams, T.L. Dickson, and S. Yin. Fracture Analysis of Vessels - Oak Ridge, FAVOR, v12.1, computer code: Theory and implementation of algorithms, methods, and correlations. ORNL/TM2012/567, USNRC Adams number ML13008A015, Oak Ridge National Laboratory, Oak Ridge, TN, November 2012.

14. Markus Niffenegger and Klaus Reichlin. The proper use of thermal expansion coefficients in finite element calculations. Nuclear Engineering and Design, 243:356-359, February 2012. 